\title{
O Fenômeno da Cronificação nos Centros de Atenção Psicossocial: Um Estudo de Caso
}

\author{
Maria da Graça Silveira Gomes da $\operatorname{Costa}^{1}$ \\ Rafael de Albuquerque Figueiró \\ Programa de Pós-Graduação em Psicologia da Universidade Federal do Rio Grande \\ do Norte, Natal, Rio Grande do Norte, Brasil \\ Curso de Psicologia da Universidade Potiguar, Natal, Rio Grande do Norte, Brasil \\ Flávia Helena Miranda de Araújo Freire \\ Universidade Federal Fluminense, Volta Redonda, Rio de Janeiro, Brasil
}

\begin{abstract}
Resumo
Os Centros de Atenção Psicossocial (CAPS) exercem um papel fundamental dentro da rede de assistência à saúde mental ao articularem os serviços e os usuários dentro do território, além de se apresentarem como um espaço privilegiado de produção de cuidado, de autonomia, e de inclusão social. No entanto, diversas pesquisas sobre o campo da Reforma Psiquiátrica no Brasil apontam para o fenômeno da nova cronificação nos serviços substitutivos de saúde mental. Assim, o presente artigo se propõe a problematizar as práticas de cuidado em um CAPS II da cidade de Natal-RN, tendo como analisador a existência dos "usuários profissionais", usuários que mantém uma relação de grande interdependência junto ao serviço, que não se articulam na comunidade e dificilmente recebem alta do CAPS. A partir da perspectiva teórico-metodológica da cartografia, investigamos como se dá a produção do usuário profissional e quais práticas sustentam esse fenômeno. Notamos que, mesmo indo contra o modelo tradicional da psiquiatria e da hospitalização, esse serviço pode gerar a institucionalização e a cronificação dos sujeitos através de métodos de organização e trabalho que seguem uma lógica hierárquica da tutela, do isolamento em relação ao meio social e da despolitização dos usuários.
\end{abstract}

Palavras-chave: Reforma psiquiátrica, saúde mental, práticas de cuidado, Centros de Atenção Psicossocial, cartografia.

\section{The Phenomenon of Chronification on Psychosocial Aid Centers: A Case Study}

\begin{abstract}
The psychosocial aid centers (CAPS) play a key role within the network of mental health assistance articulating services and users within the territory, in addition to be a privileged space for the production of care, autonomy and social inclusion. However, several researches on the field of the Psychiatric Reform in Brazil point to the phenomenon of the new chronification on the mental health substitute services. Therefore, this article purports to discuss the care practices in a CAPS II in the city of Natal$-\mathrm{RN}$, having as an analyzer the existence of the "professional users", users who maintains a relationship
\end{abstract}

Endereço para correspondência: Escola da Saúde, Universidade Potiguar, Avenida Engenheiro Roberto Freire, Capim Macio, Natal, RN, Brasil, 59082-400. E-mail: mariaggomes@gmail.com, figueiroz@hotmail.com e flaviah.freire@gmail.com 
of great interdependence with the service, which don't integrate themselves in the community and are hardly discharged from the CAPS. From the theoretical and methodological perspective of cartography, we investigate how the professional user is produced and which practices sustain this phenomenon. We noticed that, even going against the traditional model of Psychiatry and hospitalization, this service can generate the institutionalization and chronification of the subjects through methods of organization and work that follows a hierarchical logic of tutelage, isolation from the social environment and the depoliticisation of the users.

Keywords: Psychiatric reform, mental health, care practices, Psychosocial Aid Centers, cartography.

\section{El Fenómeno de la Cronicidad en los Centros de Atención Psicosocial: Un Estudio de Caso}

\section{Resumen}

Los centros de atención psicosocial (CAPS) desempeñan un papel clave dentro de la red de asistencia de salud mental articulando servicios y usuarios dentro del territorio, además de presentasen como un espacio privilegiado para la producción de cuidado, autonomía y inclusión social. Sin embargo, varias investigaciones en el campo de la Reforma Psiquiátrica en Brasil apuntan para el fenómeno de la nueva cronicidad en los servicios sustitutivos de salud mental. Así, este artículo pretende discutir las prácticas de atención en un CAPS II en la ciudad de Natal-RN, teniendo como analizador la existencia de los "usuarios profesionales", usuarios que mantienen una relación de gran interdependencia con el servicio, que no se encajan en la comunidad y difícilmente reciben alta del CAPS. Desde la perspectiva teórica y metodológica de la Cartografía, investigamos cómo el usuario profesional es producido y que prácticas sustentan este fenómeno. Tomamos nota de que, incluso yendo contra el modelo tradicional de la Psiquiatría y hospitalización, este servicio puede generar la institucionalización y cronicidad de los sujetos a través de métodos de organización y trabajo que siguen una lógica jerárquica de la tutela, del aislamiento del entorno social y de la despolitización de los usuarios.

Palabras clave: Reforma psiquiátrica, salud mental, prácticas de cuidado, Centros de Atención Psicosocial, cartografía.

O fenômeno da loucura acompanha a história da humanidade e, ao longo dela, diferentes maneiras de lidar e de compreender tal questão foram sendo forjadas. Michel Foucault (2008) revela, através de sua "genealogia da loucura", o processo de apropriação desse fenômeno pela Psiquiatria de Philippe Pinel$^{2}$ no século XIX, deslocando a experiência da loucura, que até então era essencialmente considerada uma forma de erro ou de ilusão, para a condição de doença

Philippe Pinel é visto como o médico responsável pela instituição da Psiquiatria Moderna. Seu "Tratado Médico-Filosófico sobre a Alienação Mental ou a Mania" de 1800/2007 é seminal no que se refere à classificação nosográfica dos transtornos mentais. mental (Foucault, 2006, 2008). Em consequência, dá-se a emergência de uma ordem disciplinar física e moral a vigorar principalmente nos asilos e manicômios designados como os novos espaços de circulação da "alienação mental".

O isolamento é, então, definido como princípio terapêutico, justificado pela necessidade de garantir a segurança pessoal dos loucos e suas famílias; para liberá-los das influências externas; para submetê-los ao regime médico e para impor-lhes novos hábitos intelectuais e morais (Amarante, 2003). Apenas na segunda metade do século XX, vão começar a surgir diferentes propostas que visam a transformação das práticas psiquiátricas, institucionais e hospitalocêntricas. Dentre essas propostas, a Antipsiquiatria 
e a Psiquiatria Democrática Italiana aparecem como movimentos que vão se contrapor a esse poder disciplinar da Medicina Psiquiátrica, propondo novas maneiras de lidar com a loucura, levando em conta a potência criadora, a alteridade e a contestação da sociedade trazida na figura do louco. Esses movimentos objetivavam não só o fim dos manicômios, mas o rompimento com o paradigma psiquiátrico, entendendo a loucura também enquanto fato social.

Nesse sentido, a desinstitucionalização apresenta-se como um processo de construção de uma nova política de saúde mental a partir da mobilização e participação de todos os atores interessados, tendo como foco do trabalho o enriquecimento da existência global, complexa e concreta dos usuários e a construção de estruturas externas que sejam totalmente substitutivas da internação no manicômio (Rottelli, Leonardis, Mauri, \& Risio, 1990).

Inspirando-se principalmente na Psiquiatria Democrática Italiana, o movimento da Reforma Psiquiátrica ganha força no Brasil ao final da década de 1970 denunciando os maus tratos nos manicômios, a precariedade da assistência de saúde mental e a predominância da rede privada de assistência, além de reivindicar uma mudança nos paradigmas do cuidado relativo aos sujeitos com transtornos mentais através de medidas como a diminuição dos leitos nos hospitais psiquiátricos e a implantação de serviços substitutivos de atenção como Hospitais-dia, Centros de Atenção Psicossocial (CAPS), Serviços Residenciais Terapêuticos, entre outros programas e ações de cuidado à saúde mental (Ministério da Saúde, 2004).

Promulgada em 2001, a Lei Federal 10.216, dá à Reforma Psiquiátrica Brasileira um caráter de proteção de direitos dos portadores de transtorno mental, com foco nas internações involuntárias, em detrimento da extinção progressiva dos manicômios, como enfatizava o projeto de lei 3.657 de 1989 de autoria do deputado Paulo Delgado (Ministério da Saúde, 2005). Com a publicação da portaria do Ministério da Saúde $\mathrm{n}^{\mathrm{o}} 336$ de 2002, os CAPS passam a assumir um papel de centralidade dentro do processo de reorientação do modelo assistencial, ficando estabe- lecidos os tipos de CAPS I, CAPS II, CAPS III, CAPSi e CAPS $\mathrm{AD}^{3}$, e os respectivos modos de funcionamento.

O primeiro CAPS do Brasil (CAPS Luis da Rocha Cerqueira) foi implantado na cidade de São Paulo - SP em 1987. Desde então, entraram em funcionamento no país aproximadamente 2.269 centros (Ministério da Saúde, 2013). De acordo com o Ministério da Saúde (2012), os CAPS são serviços de saúde municipais, orientados pelos princípios fundamentais do Sistema Único de Saúde (SUS) - universalidade, equidade e integralidade - abertos e comunitários, que oferecem atendimento diário à população realizando acompanhamento clínico com o objetivo de proporcionar a reinserção social dos usuários ${ }^{4}$ pelo acesso ao trabalho, lazer, exercício da cidadania e o fortalecimento dos laços familiares e sociais.

Além de prestar atendimento aos usuários e a seus familiares, esses serviços têm a incumbência de, no âmbito do seu território, articular e organizar a demanda da rede de cuidados em saúde mental; desempenhar o papel de regulador da porta de entrada da rede assistencial; coordenar as atividades de supervisão de unidades hos-

3 "CAPS I - são serviços para cidades de pequeno porte, que devem dar cobertura para toda clientela com transtornos mentais severos durante o dia (adultos, crianças e adolescentes e pessoas com problemas devido ao uso de álcool e outras drogas); CAPS II - são serviços para cidades de médio porte e atendem durante o dia clientela adulta; CAPS III - são serviços $24 \mathrm{~h}$, geralmente disponíveis em grandes cidades, que atendem clientela adulta; CAPSi - são serviços para crianças e adolescentes, em cidades de médio porte, que funcionam durante o dia; CAPS ad - são serviços para pessoas com problemas pelo uso de álcool ou outras drogas, geralmente disponíveis em cidades de médio porte. Funciona durante o dia" (Ministério da Saúde, 2012).

4 Essa terminologia é usada habitualmente para designar todos os cidadãos que utilizam o serviço do SUS. No caso especifico deste trabalho nos referiremos aos usuários que estão inseridos na rede de atenção psicossocial, entendendo que essa nomenclatura permite o abandono da expressão "paciente" que remete à condição de passividade do sujeito enquanto objeto de ações técnicas e terapêuticas. 
pitalares psiquiátricas; supervisionar e capacitar às equipes de atenção básica, serviços e programas de saúde mental, desempenhando desta forma um papel de suma importância dentro da rede de atenção psicossocial.

Para Yasui (2007) o CAPS não pode ser entendido apenas como um serviço, mas como "uma estratégia para a mudança do modelo assistencial e para a produção de cuidado e bons encontros" (Yasui, 2007, p. 155). Segundo o autor, o CAPS é um espaço privilegiado de geração de cuidados, de subjetividades mais autônomas e de inclusão social, que articula a singularidade de cada usuário à diversidade de possibilidades de intervenções terapêuticas. Desta forma, os CAPS são dispositivos importantes que podem possibilitar um processo de empoderamento dos usuários e de suas famílias, entendendo esse processo como um fortalecimento do poder pessoal e coletivo de pessoas e grupos submetidos a longo processo de dor, opressão e discriminação, como grande parte dos usuários da rede de saúde mental (Vasconcelos, 2003).

Contudo, no decorrer dos mais de dez anos da regulamentação da lei da Reforma no Brasil, vários autores (Amarante, 2007; Desviat, 1999; Pande, 2008; Severo, 2009) vêm apontando para o fenômeno da "nova" cronicidade que surge nos dispositivos substitutivos de saúde mental. Esses autores assinalam que, mesmo indo contra o modelo tradicional da psiquiatria e da hospitalização, esses serviços podem gerar a institucionalização dos sujeitos através de práticas que seguem uma lógica de tutela e despolitização.

Diante desse cenário, nos propomos a problematizar o cotidiano de um CAPS II na cidade de Natal - RN apresentando alguns elementos para análise do processo de cronificação de seus usuários, a partir da observação daquilo que denominamos como "profissionalização da loucura", fenômeno que tem dificultado maiores avanços no cenário da Reforma Psiquiátrica brasileira.

\section{Percursos Metodológicos}

Como forma de acompanhar os diversos processos que se desenrolam em um espaço pri- vilegiado de interação como o CAPS e levando em consideração a dimensão subjetiva dos acontecimentos, definimos a cartografia como guia teórico-metodológico nos caminhos trilhados.

A cartografia em questão se refere a uma geografia dos afetos, ocupando-se de um plano movente, interessando-lhe as metamorfoses e anamorfoses tomadas como processos de diferenciação nos territórios - aqui entendidos como existenciais, não consistindo na delimitação objetiva de um lugar, mas daquilo que circunscreve, para cada um, o campo do familiar e do vinculante, em uma delimitação material, rítmica e afetiva (Deleuze \& Guattari, 2005).

Segundo Rolnik (2007) o que o cartógrafo quer é "participar, embarcar na constituição de territórios existenciais, constituição de realidade" (Rolnik, 2007, p. 66). Dessa forma nos implicamos no campo, ao mesmo tempo em que nele interferimos (e somos por ele interferidos) já que, de acordo com Passos e Benevides (2010), "não há neutralidade do conhecimento, pois toda pesquisa intervém sobre a realidade mais do que a representa ou constata em um discurso cioso das evidências" (Passos \& Benevides, 2010, p. 20).

Através da experiência de estágio profissionalizante de quase um ano na Rede de Atenção Psicossocial (RAPS), entramos em contato com a realidade cotidiana de um CAPS II. Frequentamos o CAPS em média três vezes por semana, variando entre os turnos da manhã e da tarde, nos valendo da observação, participação e registro de diário de campo da rotina institucional do serviço em oficinas terapêuticas, rodas de conversa, acolhimento de novos usuários, festas dentro do serviço, assembléias gerais dos usuários, reuniões da equipe, supervisões da equipe junto aos supervisores clínico-institucionais da Secretaria Municipal de Saúde de Natal, além de eventos fora do serviço que estavam relacionados ao tema da saúde mental e contaram com a presença de usuários e profissionais do CAPS.

Em um segundo momento, elaboramos um levantamento sócio-demográfico da clientela que frequenta o CAPS, com o intuito de saber maiores informações acerca do tempo no serviço, do tratamento e das possibilidades de ar- 
ticulação com outros dispositivos do Estado e setores da comunidade. Organizamos a lista de usuários de acordo com o bairro de origem, o tempo de vinculação ao CAPS, seu diagnóstico e o tipo de tratamento (intensivo, semi-intensivo e não intensivo ${ }^{5}$.

\section{O Dia a Dia do CAPS: Cronificação do Cotidiano?}

De acordo com o decreto $\mathrm{n}^{\mathrm{o}} 7.508$ de 2011 que regulamenta a Lei ${ }^{\circ} 8.080$ de 1990, que dispõe sobre a organização do SUS, a RAPS deve funcionar de maneira integrada articulando a atenção primária (Núcleos de Atenção à Saúde da Família [NASF], Consultórios de Rua, Unidades Básicas de Saúde, etc.); a atenção psicossocial estratégica (os CAPS); a atenção de urgência e emergência (Serviço de Atendimento Móvel de Urgência [SAMU], Unidades de Pronto Atendimento 24 horas [UPAs], etc.); a atenção residencial de caráter transitório (Unidade de Acolhimento e Serviço de Atenção em Regime Residencial); a atenção hospitalar (enfermaria especializada em Hospital Geral); as estratégias de desinstitucionalização (Serviços Residenciais Terapêuticos e programa "De Volta para Casa"); e as estratégias de reabilitação psicossocial (iniciativas de geração de trabalho e renda).

Atualmente o município de Natal conta com 2 Ambulatórios de Saúde Mental (o Ambulatório de Prevenção e Tratamento do Tabagismo, Alcoolismo e outras Drogadições [APTAD] e outro para atendimento de transtornos psiquiátricos gerais); 2 Serviços Residenciais Terapêuticos (voltadas para egressos de longas internações e sem vínculos familiares); 1 Hospital Psiquiátri-

\footnotetext{
O tratamento intensivo é destinado aos usuários que estão saindo de uma situação de crise ou que chegaram recentemente ao serviço e precisam de um maior acompanhamento. Esses usuários devem frequentar o CAPS quatro vezes por semana, por um ou dois turnos. Os tratamentos semi-intensivo e não intensivo destinam-se aos usuários que já estão sendo acompanhados pela equipe e têm um quadro estável, assim eles vão ao serviço com menor frequência, dependendo da demanda de cada um.
}

co; 3 Policlínicas; 5 CAPS, sendo 2 CAPS AD, 1 CAPSi, 1 CAPS II e 1 CAPS III (o único do tipo em todo o estado do Rio Grande do Norte); 107 equipes da estratégia saúde da família (ESF) e apenas 3 equipes do NASF (Secretaria Municipal de Saúde, 2010).

Vários estudos realizados no cenário local apontam para a fragilidade da RAPS no município e para a dificuldade de articulação dos componentes que deveriam compô-la (Dimenstein et al., 2012; Pessoa, 2011; Severo \& Dimenstein, 2011). De acordo com Dimenstein et al. (2012), o número reduzido de serviços voltados ao suporte à crise; a estrutura física inadequada da maior parte dos serviços de saúde; o número reduzido de profissionais qualificados; o despreparo do SAMU no atendimento de casos de pessoas em sofrimento mental agudo; a carência de ações de promoção e cuidado em saúde mental na atenção primária; e a falta de leitos nos hospitais gerais, fazem com que o hospital psiquiátrico continue sendo uma das principais "portas de entrada" dos usuários na rede de cuidado à saúde mental no estado do Rio Grande do Norte, configurando-se como uma rede "hospital-centrada". Vemos, diante de tal cenário, que os CAPS possuem um grande desafio no que se refere ao seu funcionamento de forma integrada nessa rede.

O CAPS no qual realizamos nosso estudo foi o segundo serviço substitutivo de saúde mental implantado pela Secretaria Municipal de Saúde de Natal, no ano de 1995. O serviço possui 17 profissionais na equipe, entre trabalhadores de nível básico, médio e superior, sendo três cozinheiras, dois vigias, uma copeira, duas enfermeiras, uma terapeuta ocupacional, uma nutricionista, um pedagogo, um educador físico, duas psicólogas, dois médicos e dois farmacêuticos, atendendo oficialmente, por volta de 180 usuários (o número de usuários pode variar bastante de acordo com a demanda) de segunda a sexta, das 8 horas às 17 horas. Nas quartas-feiras o CAPS não é aberto aos usuários, pois é reservado para expediente interno e reunião de equipe, salvo nas primeiras quartas do mês, quando há assembleia geral.

A entrada dos novos usuários no serviço é feita a partir de uma entrevista que ocorre com 
a participação de dois técnicos que colhem informações sobre a história pessoal e familiar dos usuários, histórico do transtorno mental, itinerário terapêutico, entre outros aspectos. Dessa forma, o ingresso do usuário está condicionado à adequação nosológica psiquiátrica específica. Além disso, muitas vezes os usuários têm de enfrentar uma "lista de espera", por conta da dificuldade do serviço em acolher o contingente da demanda que é maior que a sua capacidade, sendo que, a cada ano, diminuem a porcentagem de admissões e altas de usuários no serviço.

É importante ressaltar que a equipe do CAPS II não entende que esse seja um serviço de referência no atendimento e suporte às crises psiquiátricas, de forma que nesses casos os usuários são encaminhados preferencialmente para o CAPS III e o hospital psiquiátrico. Nessas situações o acompanhamento do caso cabe ao técnico de referência do usuário.

Logo nos primeiros dias de convivência, nos chamou a atenção a dinâmica das refeições coletivas que, como apontam Alverga e Dimenstein (2006), é um importante analisador para entender os territórios existenciais das interações que se constroem nas minúcias do cotidiano dos serviços. As refeições são servidas em espaços separados para técnicos e usuários. Enquanto os técnicos almoçam ou lancham na cozinha (espaço interditado aos usuários) e no pátio da entrada do CAPS, os usuários comem em uma mesa grande próxima ao quintal. Os talheres, os copos e até a água para beber são separados entre aquilo que é dos usuários e aquilo é dos técnicos, e, nas poucas ocasiões em que lanchamos junto com os usuários ou usamos os mesmos talheres, fomos duramente repreendidos pelo restante da equipe.

Apesar de compreendermos que a separação entre usuários e técnicos pode ser uma estratégia para organizar as refeições, além de servir como um momento de descanso para os trabalhadores do serviço, a existência de uma proibição sobre esse tipo de relação entre os usuários e os integrantes da equipe (que desejavam o contrário) nos causou estranhamento. Percebemos, dessa forma, que a relação estabelecida entre técnicos e usuários é bastante hierarquizada, de forma que, ao invés de desinstitucionalizar o paradigma manicomial, parece reforçá-lo.

Para Golberg (2001), o princípio norteador de atuação no CAPS, dentro do conjunto da Reforma, é o da reabilitação como um "processo articulado de práticas (sustentadas por uma trama de conceitos), que não se deteria até que a pessoa acometida por problemas mentais pudesse sedimentar uma relação mais autônoma com a instituição" (Golberg, 2001, p. 34). Assim, o tratamento dos usuários deve ser desenvolvido respeitando o tempo e incentivando a participação dos mesmos em seus próprios processos terapêuticos.

As atividades do CAPS em questão, no entanto, são planejadas pela equipe em reuniões internas, quando não há usuários no serviço, fato também notado por Figueiró e Dimenstein (2010), que a partir dessa observação se questionam sobre como se pode pensar o cotidiano de um equipamento em condições irreais:

Irreal no sentido de extraordinário, já que tal conjuntura, a presença exclusiva dos técnicos, não faz parte da realidade de um CAPS, e, em nossa opinião, nem deve fazer. Um equipamento de saúde só tem sentido com a presença de seus usuários, principais atores ... daquele espaço. (Figueiró \& Dimenstein, 2010, p. 434)

Diante da não participação dos usuários na gestão do cotidiano do serviço, várias estratégias de atuação são elaboradas sem levar em conta as demandas dos mesmos. O dia a dia do CAPS é normalmente preenchido com oficinas de artesanato e/ou de escrita e rodas de conversas chamadas de "encontro de ideias", onde, com a mediação dos técnicos, os usuários contam ao grupo sobre o fim de semana anterior ou sobre alguma novidade em suas vidas. Kastrup e Benevides (2009) apresentam as oficinas artísticas como dispositivos que permitem o agenciamento, através dos materiais, de uma subjetividade e uma aprendizagem-inventiva.

As oficinas, portanto, devem ser pensadas como estratégias que visam o objetivo de produzir possibilidades nos sujeitos, compondo a teia de dispositivos que tem como meta final a reabilitação psicossocial dos usuários. No en- 
tanto, as oficinas no CAPS são pensadas não a partir de demandas e objetivos, mas a partir das habilidades e disposição de quem as estão conduzindo. Diante da falta de profissionais ligados à terapia ocupacional, à música, à arteterapia, à dança, etc., a elaboração e condução das oficinas ficavam a cargo do técnico (ou estagiário) que estivesse disponível no momento. Como observamos, essas atividades acabavam servindo como um "passatempo" tanto para os usuários quanto para os profissionais do CAPS.

Na maioria das vezes percebemos que há um esvaziamento nesses momentos. Frente a pouca participação e interesse dos usuários, os técnicos tentavam persuadi-los a participar das atividades através da utilização de vários recursos, inclusive com pequenas ameaças - certa vez, ouvimos de uma técnica: "Aqui nós temos um combinado que quem não participa das atividades não lancha".

A elaboração de oficinas que não levam em consideração o desejo e a demanda dos usuários e o uso da ameaça de penalização como um recurso por parte dos técnicos é um exemplo de prática alienante do cotidiano, que não está de acordo com a ideia de reinserção social e, principalmente, com a noção de desinstitucionalização a que o serviço se propõe, e mostra como o funcionamento do trabalho está alicerçado na manutenção da tutela em relação aos usuários e do poder/saber nas mãos dos profissionais.

No mesmo sentido, percebemos que a falta de projetos terapêuticos singulares (PTS) inviabiliza a elaboração de estratégias de cuidado para com os usuários do serviço. O PTS funciona como um conjunto de propostas de condutas terapêuticas articuladas, para um sujeito individual ou coletivo, resultado da discussão coletiva de uma equipe interdisciplinar, com apoio matricial quando necessário (Ministério da Saúde, 2008).

Portanto, entende-se que a elaboração de PTS junto aos usuários e suas famílias, levando em conta seus anseios e particularidades, é um artifício importante no aumento da autonomia desses sujeitos, pois permite que eles façam escolhas e estabeleçam normas para sua própria vida. Essa discussão foi trazida para a equipe do CAPS II através das reuniões de supervisão clínico-institucional da Secretaria Municipal de Saúde, contudo a elaboração de PTS foi colocada em prática de maneira insipiente nos métodos de trabalho, de forma que a realidade do serviço não condiz em vários aspectos com as necessidades de muitos ali presentes.

Junto ao projeto de elaboração do PTS surgiu o projeto de realizar o apoio matricial junto às equipes da ESF dos territórios em que vivem os usuários, dialogando com suas equipes de referência da atenção primária à saúde. $\mathrm{O}$ apoio matricial é uma estratégia de gestão para a construção de uma rede ampla de cuidados em saúde mental, desviando a lógica de encaminhamentos indiscriminados para uma lógica da co-responsabilização entre os diferentes níveis de atenção à saúde, sendo um dispositivo articulador de um conjunto de estratégias fundamentais no processo de construção e transformação da assistência em saúde mental (Bezerra \& Dimenstein, 2008).

A partir das reuniões e supervisões para a implantação dessa estratégia, um processo de "pensar sobre" a sistematização do trabalho fez com que a equipe se organizasse, redefinindo metas e dialogando mais. Esse processo mostrou-se ser um dispositivo potencializador do coletivo-equipe do CAPS. Entretanto, depois de 06 meses de discussões internas e junto às equipes da ESF, essa prática foi sendo, gradativamente, deixada de lado, devido a uma série de problemas como falta de transporte para visitação das equipes, o número de profissionais do CAPS, a dificuldade de comunicação com as equipes da ESF, entre outros.

Segundo Merhy (2001), é essencial que os trabalhadores da saúde sejam capazes de intervir de forma a satisfazer a necessidade e os direitos dos usuários de acordo com as suas realidades. O processo de trabalho que procura resolver os "problemas de saúde" nem sempre é um processo produtivo que implica ganhos dos graus de autonomia no sentido de o usuário gerir sua própria vida, algo que Merhy (2001) entende como saúde em última instância, pois aquele processo de produção de atos de saúde pode simplesmente ser "procedimento-centrado" e não "usuário-centrado", onde a finalidade última pela qual ela se realiza se esgota na produção de um pacien- 
te operado e "ponto final", ou, em um paciente diagnosticado organicamente e "ponto final": "Nós enquanto usuários podemos ser operados, examinados, etc., sem que com isso tenhamos necessidades/direitos satisfeitos" (Merhy, 2001, p. 8).

Essa dissociação entre a organização do trabalho e as necessidades dos usuários se traduz na pouca participação desses últimos em grupos de conversa, na prática mecânica em oficinas, e, principalmente, no sentimento de obrigação, por parte de alguns, de frequentar o serviço. Muitos usuários chegam a chamar o CAPS II de "esco$l a "$ e os profissionais da equipe de "tio" e "tia", algo que não é problematizado nas reuniões da equipe, nas assembléias gerais e nem na reunião com familiares.

Nas assembleias, comumente, discute-se questões do funcionamento interno do serviço, tal como falta de medicamentos, de água ou de gás, três itens que estiveram em falta, com certa regularidade, durante o ano que estivemos acompanhando o serviço. As assembléias também são um espaço onde são dados informes para os usuários sobre eventos ligados ao CAPS. Porém, pouco é discutido nessas reuniões em relação aos assuntos que envolvam o serviço em um contexto mais geral, o que mostra uma despolitização e despotencialização desse dispositivo que poderia funcionar como um espaço de exercício de cidadania.

Da mesma forma, tampouco se discute sobre as políticas de saúde, e, mais especificamente, de saúde mental, levando-nos a crer que existe um grande processo de "alheamento" dos sujeitos em relação a seus contextos econômicos, históricos e sociais, processo esse que nos parece ser incentivado, mesmo que de forma não deliberada, pela equipe do serviço. Um exemplo significativo disso é o fato de que os profissionais e usuários entendem e se referem ao dia 18 de maio, dia internacional da luta antimanicomial, como se fosse um feriado do serviço, havendo pouco debate sobre a importância política e simbólica dessa data.

Parece ser consenso entre todos que o espaço onde são tomadas as decisões é o das reuniões de equipe, das quais os usuários e familiares não podem participar, de forma que aquilo que é decidido em assembleia geral tem de passar pela equipe, em um momento a parte, para ser ou não legitimado. Ao mesmo tempo, nas assembleias, percebemos que os usuários e familiares são pouco propositivos, se contentando em aceitar ou rejeitar aquilo que é proposto pelos profissionais, conforme já sinalizado por Figueiró e Dimenstein (2010).

Tal funcionamento, centrado na heterogestão ${ }^{6}$ do cotidiano, coloca o poder de decisão acerca do funcionamento do serviço nas mãos dos técnicos, reforçando assim uma relação de tutela, o que diminui as possibilidades de empoderamento daquele coletivo, podendo fazer com que o CAPS se torne um espaço cronificante e despotencializador no que se refere à produção de vida para os usuários.

\section{Os "Usuários Profissionais": A História de Raimunda"}

Durante a experiência de estágio pôde-se perceber, de modo geral, como se dão as práticas de cuidado dentro do serviço. Essas observações do funcionamento do CAPS nos despertaram vários questionamentos e inquietações, ou, como diria Rolnik (1993), "linhas de desassossego" que foram traçadas criando rupturas na maneira como enxergávamos o trabalho em saúde mental. Dentre os analisadores dos processos em movimento no campo, passamos a notar que muitos daqueles que frequentam o serviço se "especializam" na função de usuários da rede de atenção à saúde mental, tornando-se o que chamamos de "usuários profissionais". Em geral, esses usuários se caracterizam por frequentar o serviço há muitos anos e manter uma relação de interde-

6 Conceito utilizado pela Administração que se refere a um tipo de gestão oposta à autogestão, isto é, a gestão é gerida por outra pessoa, que pode ser um gerente, dono de empresa, ou no caso de instituições públicas, os gestores. Esse modelo, portanto, dificulta o controle social a participação do usuário no processo de gestão democrática dos serviços de saúde preconizadas pelo SUS.

7 Utilizamos um nome fictício para preservar a identidade da usuária. 
pendência com os técnicos, o que lhes confere uma autoridade em relação aos outros usuários e à equipe.

No levantamento que elaboramos sobre a clientela que frequenta o CAPS, contabilizamos mais de trinta usuários que estão em tratamento intensivo (vão ao serviço de duas a quatro vezes por semana) desde a inauguração do CAPS. Para explicitar esse fenômeno, tomaremos como exemplo a história de Raimunda.

Raimunda, de 46 anos de idade, é usuária do CAPS desde o início do serviço. Solteira e sem filhos, ela vive em um quartinho separado na casa do pai e da madrasta em Felipe Camarão, bairro periférico da cidade de Natal.

De acordo com seu prontuário, o diagnóstico de Raimunda aponta para a presença de um transtorno de personalidade paranoica. Ela teve sua primeira crise aos 12 anos de idade, depois do falecimento de sua mãe, quando se mudou para Natal, vinda da área rural do estado. A partir de então ela teria começado a apresentar crises epilépticas, agressividade, anorexia e automutilação, que a levaram a ter várias internações psiquiátricas.

Raimunda é bastante comunicativa, gosta de atuar nas peças de teatro organizadas em dias de festa no serviço e, apesar de ter uma certa dificuldade de locomoção devido a uma pequena trombose em uma das pernas, não tem problemas para andar de ônibus, sozinha, por toda a cidade. A equipe a descrevia como uma pessoa manipuladora, carente, ansiosa e que, aparentemente, não apresentava crises graves há vários anos. Segundo os relatos dos profissionais mais antigos, Raimunda teve um considerável ganho de autonomia desde que entrou no CAPS, no entanto, mesmo estável, ela nunca deixou de frequentar, quase diariamente, o serviço.

Passamos a prestar uma atenção especial ao seu caso, quando em uma supervisão, diante da sugestão do supervisor clínico-institucional de dar alta à Raimunda, quase todos os técnicos foram contra, argumentando que a mesma entraria em crise ao se desligar do CAPS, pois, de acordo com a fala de um técnico: "ela não estaria preparada para sair". Poucos dias depois dessa reunião, coincidentemente, Raimunda comentou enquanto conversávamos no pátio: "Deus me livre de sair do CAPS. O que eu faria se não viesse para cá?". Ao propor que ela se inserisse em outros espaços, como no grupo de teatro da associação de moradores de seu bairro, ela respondeu que não tinha interesse, pois o território onde se sentia segura era o CAPS. Ela também dizia não se dar bem com o pai e a madrasta e que, por isso, não gostava de ficar em casa e assim ia para o serviço.

Houve tentativas de diminuir a frequência de idas da usuária, que passaria do regime de tratamento intensivo para o semi-intensivo e posteriormente o não intensivo, porém, sem o uso de estratégias específicas pensadas para ela, Raimunda continua voltando várias vezes por semana, alegando os mais diversos motivos. Presenciamos algumas ocasiões em que a usuária chegava depois do horário do almoço, afirmando que estava por perto do CAPS e resolvera visitar a equipe. A equipe muitas vezes a ignorava, no entanto não apresentava objeção à sua presença ali. Já os outros usuários tinham uma relação difícil com Raimunda, mesmo que ela fizesse questão de afirmar que era amiga de todos.

Em eventos fora do serviço, um dos técnicos sempre pedia pra que Raimunda "tomasse conta" de outros usuários e isso parecia incomodá-los bastante, pois alguns questionavam por que ela, também usuária, tinha um poder de tutela semelhante aos profissionais do serviço. Ela também costumava contar para os técnicos sobre qualquer conduta dos outros usuários que fosse considerada errada e isso gerava ainda mais conflitos. À Raimunda, também eram concedidos alguns privilégios, como o acesso ao espaço da cozinha, por exemplo, que como já mencionamos anteriormente, era proibido para a maioria dos usuários do CAPS.

O caso de Raimunda nos chama atenção por diversos motivos. Da mesma forma que grande parte dos usuários, ela admite que o CAPS transformou-se em seu único espaço de convivência - é importante lembrar que um dos trabalhos do CAPS é o de articular as redes de apoio social no território. Assim, notamos que a saída dos usuários do serviço não parece ser um recurso possível, chegando a ser temida pelos técnicos, mos- 
trando que existe uma relação de dependência mútua: usuário-dependente/ serviço-dependente.

Segundo Severo (2009) a rede especializada de cuidado à saúde mental, tal como os CAPS e ambulatórios de saúde mental, parece se constituir como o único espaço que permite a sociabilidade entre seus usuários, que muitas vezes ficam restritos ao "circuito especial" (rede especializada de serviços de saúde mental - domicílio) o que pode gerar uma dependência destes em relação a esses serviços, além de indicar a existência de uma cronificação dos usuários dentro da rede. Ao mesmo tempo, essa permanência indiscriminada no serviço gera excesso de demanda e, consequentemente, a incapacidade dos profissionais de atenderem satisfatoriamente a população.

O caso de Raimunda também nos chama atenção à falta de articulação entre a rede especializada de cuidado em saúde mental e a atenção primária no município, o que dificulta sobremaneira a prática de matriciamento e o desenvolvimento de ações compartilhadas entre as equipes da ESF, dos NASF e dos serviços substitutivos nos territórios de vinculação dos usuários. Apesar de Raimunda morar em uma área que conta com cobertura da ESF e do NASF, não houve diálogo com as equipes do seu território para pensar as estratégias a serem desenvolvidas junto à usuária para que pudesse se vincular a outros dispositivos sociais e serviços públicos.

A existência dos usuários de longa permanência, como Raimunda, representa um desafio ao projeto da Reforma Psiquiátrica, pois mostra os entraves no desenvolvimento do modelo integral de saúde pensado pelo SUS e a dificuldade dos serviços substitutivos em articular verdadeiramente esses usuários ao meio social promovendo a reinserção psicossocial, ao reproduzir a lógica de exclusão ao restringir a vida dos sujeitos aos espaços exclusivos de circulação da loucura.

De acordo com Amarante (2007), os novos serviços de atenção psicossocial podem funcionar como "instituições totais como metáfora" no sentido em que podem concentrar atividades importantes da vida do usuário geralmente realizadas em espaços distintos, como vínculos afetivos, tratamento, trabalho, alimentação, lazer, o que implica em uma espécie de ruptura com o mundo externo.

Desse modo, não há projetos, mesmo que pontuais, de saída do CAPS, nem de visita domiciliares, salvo quando há caminhadas em um parque municipal - que fica há poucos metros do serviço - coordenadas pelo educador físico. Apesar de Raimunda residir em um bairro com diversos dispositivos sociais que possivelmente poderiam mobilizar a usuária, como o grupo de teatro, nunca se pensou em tal inserção comunitária como uma estratégia efetiva de cuidado para a usuária.

A relação entre Raimunda e os funcionários do CAPS aponta ainda para o processo de "infantilização" dos usuários. Os técnicos, ao estabelecerem a figura de Raimunda como "dedo-duro" do grupo - que por tal razão goza de certo capital social e moral entre os funcionários - reafirmam a necessidade da tutela e da hierarquia naquele espaço, reproduzindo, mais uma vez, uma lógica do CAPS-escola.

O cenário em questão corrobora com aquilo que nos assinala Rangel (2008). Segundo a autora, três pontos parecem ser especialmente relevantes quando se trata da contribuição do serviço para a cronicidade dos usuários. São eles: a "infantilização" dos usuários; o aparente isolamento do serviço em relação à comunidade; e finalmente, as relações hierárquicas entre técnicos e usuários.

Vale enfatizar, entretanto, que o aumento da autonomia dos usuários é diferente de independência, pois somos todos dependentes de algo e de alguém. Concordamos com Kinoshita (2001) que o mais importante é que se possa desenvolver uma pluralidade de dependências, um mundo rico de possibilidades, de forma que não se fique preso a algo específico, como um serviço ou determinados técnicos, por exemplo. A desvinculação do serviço não implica necessariamente em uma nova relação dos usuários com o mundo exterior, no sentido de estabelecer autonomia, independência, ampliação das relações sociais e dos vínculos afetivos. Essa articulação deve ser tomada também como uma prática de cuidado e de saúde, assim como a Reforma Psiquiátrica deve se expandir para além dos serviços de saú- 
de e da comunidade para se efetivar também no âmbito sociocultural.

Considerando que os CAPS se constituem como carros-chefe da Reforma Psiquiátrica brasileira, torna-se urgente problematizar o modo como vem funcionando seus cotidianos, sua micropolítica. Acreditamos que esses serviços devem se constituir enquanto dispositivos produtores de subjetividades, capazes de agenciar práticas de cuidado que permitam o empoderamento dos usuários, possibilitando a produção de saúde e de uma vida mais potente, dentro e fora do serviço.

\section{Considerações Finais}

O presente trabalho se propôs a problematizar o fenômeno da cronificação do cotidiano e dos usuários em equipamentos de saúde mental como o CAPS. Acreditamos que as práticas da tutela, da hierarquização entre usuários e profissionais e da não articulação entre serviço e sociedade, sustentam a existência do fenômeno da cronificação dos usuários, que não desenvolvem autonomia e desinstitucionalização como é desejado no projeto institucional, político e cultural da Reforma Psiquiátrica.

O processo de desinstitucionalização não se refere apenas à desospitalização dos sujeitos, mas sim à construção de práticas e saberes que produzam determinadas formas de perceber, entender e relacionar-se com os fenômenos sociais e históricos. Para tanto, é preciso problematizar as bases do saber psiquiátrico e a função social e política desempenhada pela ciência, pelos técnicos e pelo manicômio (Saraceno, 2001).

Para Rottelli et al. (1990), o verdadeiro objeto da Reforma Psiquiátrica deve ser o entendimento do sofrimento dos pacientes em sua relação com o corpo social. A desinstitucionalização, segundo ele, seria um processo prático-crítico que reorientaria as instituições e serviços, energias e saberes, estratégias e intervenções em direção ao processo de singularização e ressingularização dos sujeitos.

Segundo Merhy (2001), no trabalho em saúde e no ato do cuidado, existe uma tensão per- manente da relação tutelar e libertadora. Para o autor, o ato cuidador é centralmente um ato de tutela outorgada, que poderá, conforme o modelo de intervenção, ser ou não castradora. Também no CAPS percebemos essa tensão e vemos que quando as intervenções e a construção das práticas no serviço não levam em conta o mundo das necessidades/direitos dos usuários, e as necessidades trazidas pelos usuários são julgadas e catalogadas como adequadas ou não ao tipo de serviço que se oferece, a tutela torna-se castradora de desejos, impedindo os usuários de se empoderarem politicamente e afetivamente, de forma a produzir percursos que invistam no mundo, para torná-lo e tomá-lo, em parte, como seu (Merhy, 2001; Merhy, Feuerwerker, \& Gomes, 2010).

Por fim, queremos enfatizar que as reflexões aqui apresentadas não objetivam julgar o valor do trabalho que vem sendo realizado nos CAPS. Enxergamos esses serviços também como espaços de luta contra concepções hegemônicas de cuidado pautadas na lógica manicomial. Por isso, buscamos através da problematização das questões levantadas, reafirmar a potência e as possibilidades que esses dispositivos apresentam para o processo de desinstitucionalização e afirmação da cidadania daqueles considerados loucos, entendendo que os serviços substitutivos de saúde mental, tais como o CAPS, devem se apresentar não como "espaços-fim", mas como "espaços-meio" que possibilitem a inserção de outros modos de existência na sociedade.

\section{Referências}

Alverga, A., \& Dimenstein, M. (2006). A reforma psiquiátrica e os desafios na desinstitucionalização da loucura. Interface - Comunicação, Saúde, Educação, 10(20), 299-316. doi:10.1590/ S1414-32832006000200003

Amarante, P. (2003). Saúde mental - Políticas e instituições: Programa de Educação a Distância. Rio de Janeiro, RJ: Editora da Fundação Oswaldo Cruz.

Amarante, P. (2007). Saúde mental e atenção psicossocial. Rio de Janeiro, RJ: Editora da Fundação Oswaldo Cruz. 
Bezerra, E., \& Dimenstein, M. (2008). Os CAPS e o trabalho em rede: Tecendo o apoio matricial na atenção básica. Psicologia: Ciência e Profissão, 28(3), 632-645. doi:10.1590/S141498932008000300015

Decreto $\mathrm{n}^{\circ} 7.508$ de 2011. (2011, 29 maio). Regulamenta a Lei no 8.080, de 19 de setembro de 1990, para dispor sobre a organização do Sistema Único de Saúde - SUS, o planejamento da saúde, a assistência à saúde e a articulação interfederativa, e dá outras providências. Diário Oficial da União. Recuperado em http://www. planalto.gov.br/ccivil_03/_ato2011-2014/2011/ decreto/D7508.htm

Deleuze, G., \& Guattari, F. (2005). Mil platôs: Capitalismo e esquizofrenia: Vol. 4. Rio de Janeiro, RJ: Editora 34

Desviat, M. (1999). A reforma psiquiátrica. Rio de Janeiro, RJ: Editora da Fundação Oswaldo Cruz.

Dimenstein, M., Amorim, A. K. A., Leite, J., Siqueira, K., Gruska, V., Vieira, C., ...Bezerril, M. C. (2012). O atendimento da crise nos diversos componentes da rede de atenção psicossocial em Natal/RN. Polis e Psique, 2(1), 95-127.

Figueiró, R., \& Dimenstein, M. (2010). O cotidiano de CAPS: Empoderamento ou captura? Fractal: Revista de Psicologia, 22(2), 431-446. doi:10.1590/S1984-02922010000800015

Foucault, M. (2006). O poder psiquiátrico. São Paulo, SP: Martins Fontes.

Foucault, M. (2008). A história da loucura na idade clássica. São Paulo, SP: Perspectiva.

Golberg, J. (2001). Reabilitação como processo - O centro de atenção psicossocial - CAPS. In A. Pitta (Ed.), Reabilitação psicossocial no Brasil (pp. 33-47). São Paulo, SP: Hucitec.

Kastrup, V., \& Benevides, R. (2009). Movimentos-funções dos dispositivos na prática da cartografia. In E. Passos, V. Kastrup, \& L. Escóssia (Eds.), Pistas do método da cartografia: Pesquisa-intervenção e produção de subjetividade (pp. 76-91). Porto Alegre, RS: Sulina.

Kinoshita, R. T. (2001). Contratualidade e reabilitação psicossocial. In A. Pitta (Ed.), Reabilitação psicossocial no Brasil (pp. 55-59). São Paulo, SP: Hucitec.

Lei $\mathrm{N}^{\circ}$ 8.080, de 19 de setembro de 1990. (1990, 20 set.). Dispõe sobre as condições para a promoção, proteção e recuperação da saúde, a or- ganização e o funcionamento dos serviços correspondentes e dá outras providências. Diário Oficial da União. Recuperado em http://www. planalto.gov.br/ccivil_03/leis/18080.htm

Lei $\mathrm{N}^{\circ}$ 10.216, de 6 de abril de 2001. (2001, 9 abr.). Dispõe sobre a proteção e os direitos das pessoas portadoras de transtornos mentais e redireciona o modelo assistencial em saúde mental. Diário Oficial da União. Recuperado em http://www. planalto.gov.br/ccivil_03/leis/leis_2001/110216. htm

Merhy, E. E. (2001). Realizar no micro a luta do macro: $O$ ato de cuidar, um agir tutelar e automizador. Salvador, BA: Crobrem. Recuperado em http://www.eeaac.uff.br/professores/merhy/ artigos-09.pdf

Merhy, E. E., Feuerwerker, L. M., \& Gomes, M. P. (2010). Da repetição à diferença: Construindo sentidos com o outro no mundo do cuidado. In T. B Franco \& V. C. Ramos (Eds.), Semiótica, afeccção \& Cuidado em saúde (pp. 60-75). São Paulo, SP: Hucitec.

Ministério da Saúde. (2004). Legislação em saúde mental: 1990-2004. Brasília, DF: Autor.

Ministério da Saúde. (2005). Reforma psiquiátrica e política de saúde mental no Brasil. Brasília, DF: Organização Panamericana de Saúde.

Ministério da Saúde. (2008). Clínica ampliada, equipe de referência e projeto terapêutico singular. Brasília, DF: Autor.

Ministério da Saúde. (2012). Tipos de CAPS. Recuperado em http://portal.saude.gov.br/portal/saude/ visualizar_texto.cfm?idtxt $=33882$

Ministério da Saúde. (2013). Quantidade segundo região, tipo de estabelecimento: Centro de Atenção Psicossocial-CAPS. Recuperado em http:// tabnet.datasus.gov.br/cgi/tabcgi.exe?cnes/cnv/ estabbr.def

Passos, E., \& Benevides, R. (2010). A cartografia como método de pesquisa-intervenção. In E. Passos, V. Kastrup, \& L. Escóssia (Eds.), Pistas do método da cartografia: Pesquisa-intervenção e produção de subjetividade (pp. 17-31). Porto Alegre, RS: Sulina.

Pessoa, J. M., Jr. (2011). Trajetória do hospital dia Dr. Elger Nunes: Um recorte histórico da psiquiatria e saúde mental no Rio Grande do Norte (Dissertação de mestrado, Universidade Federal do Rio Grande do Norte, Natal, RN, Brasil). Re- 
cuperado em http://www.natal.rn.gov.br/bvn/ publicacoes/JoaoMPJ.pdf

Pinel, P. (2007). Tratado médico-filosófico sobre a alienação mental ou a mania (J. C. Galli, Trad.). Porto Alegre, RS: Editora da Universidade Federal do Rio Grande do Sul. (Original publicado em 1800)

Portaria GM n ${ }^{\circ} 336$, de 19 de fevereiro de 2002. (2002, 20 fev.). Define e estabelece diretrizes para o funcionamento dos Centros de Atenção Psicossocial. Diário Oficial da União.

Rangel, M. (2008). A "nova cronicidade" nos "novos" Serviços de Atenção Psicossocial (Dissertação de mestrado, Escola Nacional de Saúde Pública Sergio Arouca, Rio de Janeiro, RJ, Brasil). Recuperado em http://bvssp.icict.fiocruz.br/ lildbi/docsonline/get.php?id=1485

Rolnik, S. (1993). Pensamento, corpo e devir: Uma perspectiva ético/estético/ política no trabalho acadêmico. Cadernos de Subjetividade, 1(2), 241-250

Rolnik, S. (2007). Cartografia sentimental: Transformações contemporâneas do desejo. Porto Alegre, RS: Sulina.

Rottelli, F., Leonardis, O., Mauri, D., \& Risio, C. (1990). Desinstitucionalização, uma outra via. In F. Nicáfio (Ed.), Desinstitucionalização (pp. 17-61). São Paulo, SP: Hucitec.

Saraceno, B. (2001). Reabilitação psicossocial: Uma prática à espera de teoria. In A. Pitta (Ed.), Reabilitação psicossocial no Brasil (pp. 150-154). São Paulo, SP: Hucitec.
Secretaria Municipal de Saúde. (2010). Relatório de gestão. Natal, RN: Autor. Recuperado em http:// www.natal.rn.gov.br/sms/paginas/File/relatorios-de-gestao/relatorio_de_gestao_sms_2010. pdf

Severo, A. K. (2009). A cronificação nos serviços substitutivos na rede de saúde mental de Natal - $R N$ (Dissertação de mestrado, Universidade Federal do Rio Grande do Norte, Natal, RN, Brasil). Recuperado em ftp://ftp.ufrn.br/pub/ biblioteca/ext/bdtd/AnaKS.pdf

Severo, A. K., \& Dimenstein, M. (2011). Rede e intersetorialidade na atenção psicossocial: Contextualizando o papel do ambulatório de saúde mental. Psicologia: Ciência e Profissão, 31(3), 640-655. doi:10.1590/S1414-98932011000300015

Vasconcelos, E. M. (2003). O poder que brota da dor e da opressão: Empowerment, sua história, teorias e estratégias. São Paulo, SP: Paulus.

Yasui, S. (2007). CAPS: Estratégia de produção de cuidados e de bons encontros. In R. Pinheiro, A. P. Guljor, A. Gomes, \& R. A. Mattos (Eds.), Desinstitucionalização em saúde mental: Contribuições para estudos avaliativos (pp. 155-167). Rio de Janeiro, RJ: Centro de Estudos e Pesquisa em Saúde Coletiva. 